\title{
Thrombophilia in a man with long-standing hypogonadism
}

\author{
LR Ranganath, L Jones, AG Lim, SR Gould, PF Goddard
}

A 60-year-old man, in apparently previous good health, presented to hospital with acute pleuritic chest pain. Investigation revealed ventilation-perfusion inequalities consistent with the diagnosis of pulmonary embolism. He was successfully anticoagulated and made a complete recovery. During his hospitalisation he was noted to have an eunuchoid skeletal habitus, small atrophic testes, a stretched penile shaft length of $3 \mathrm{~cm}$, marked gynaecomastia and scanty body hair. He was infertile and had experienced erectile failure all his life. He did not suffer from anosmia or visual disturbances. He had lost approximately $6.3 \mathrm{~cm}$ in height suggestive of vertebral crush fractures. His height, pubis to feet, pubis to vertex and arm span measurements were $163.8,88.8$, 75 and $190 \mathrm{~cm}$, respectively. He was obese (weight $90 \mathrm{~kg}, \mathrm{BMI} 32.1$ ) with a barrel chest. His pulse was 72 beats/min, regular, and all accessible peripheral pulses were palpable. His blood pressure was consistently elevated at $210 / 110 \mathrm{mmHg}$. He had a waddling gait suggestive of proximal myopathy that was painless. He was unable to squat or raise himself from a chair without the use of his upper limbs. He had difficulty climbing stairs. He had moderate bilateral wasting of his thighs and buttocks although his upper limbs and the distal lower limbs were relatively unaffected. He had chronic obstructive airways disease for which he took salbutamol as inhaler and he had smoked 20-30 cigarettes daily all his adult life.

Karyotyping revealed a mosaic form of XXY ( $19 \%$ of counted cells were XXY). Routine haematological and biochemical investigations were all normal. In particular, in view of the myopathy, the serum potassium, calcium and creatine kinase were all normal. Serum testosterone, luteinising hormone $(\mathrm{LH})$ and follicle-stimulating hormone (FSH) were undetectable. His thoracolumbar spine $\mathrm{X}$-ray is shown in the figure.

\author{
Epsom General \\ Hospital, \\ Epsom, Surrey, \\ KT18 7EG, UK \\ Department of \\ Chemical Pathology \\ LR Ranganath \\ PF Goddard \\ Department of \\ Haematology \\ L Jones \\ Department of \\ Medicine \\ AG Lim \\ SR Gould
}

Accepted 4 March 1997

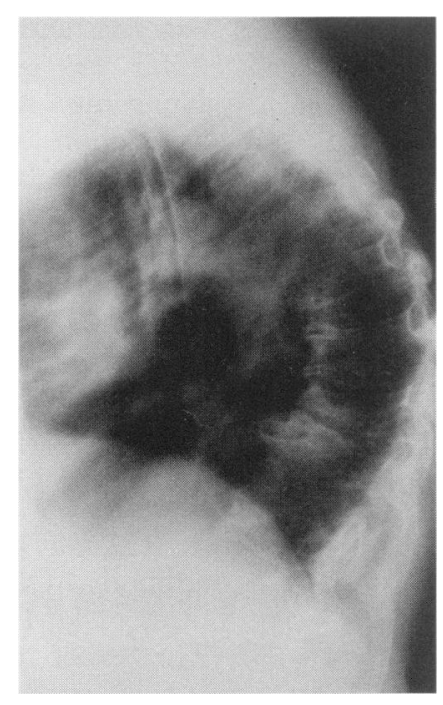

\section{Questions}

1 What is the diagnosis?

2 What two complications of the disease are present in this patient?

3 What four further investigations should be carried out ?

4 How should this patient be treated ?
Figure Lateral X-ray of thoracic spine showing advanced osteoporosis 


\section{Answers}

\section{QUESTION 1}

Karyotyping confirms the diagnosis of Klinefelter's syndrome in this man. However, the undetectable gonadotropins indicates the possibility of hypopituitarism.

\section{QUESTION 2}

Osteoporosis and myopathy are both well described complications of androgen deficiency.

\section{QUESTION 3}

Assessment of pituitary function (table 1), magnetic resonance imaging (MRI) of the pituitary, thrombophilia screen (table 2), and bone densitometry (to monitor bone mass).

\section{QUESTION 4}

The patient should receive testosterone replacement, bisphosphonate and low-dose aspirin therapy.

Table 1 Combined synacthen $(250 \mu \mathrm{g}) / \mathrm{TRH} \quad(200 \mu \mathrm{g}) / \mathrm{LHRH}$ $(100 \mu \mathrm{g})$ stimulation test

\begin{tabular}{lllll}
\hline Time (min) & 0 & 30 & 60 & \\
Cortisol (nmol/l) & 361 & 828 & 973 & \\
LH (IU/l) & $<1$ & 2 & 3 & \\
FSH (IU/l) & 2 & 3 & 5 & \\
TSH (mIU/l) & 1.1 & 2.5 & 2.2 & Reference range \\
Prolactin (mIU/l) & 127 & 198 & 148 & $(50-160)$ \\
& & & & Result \\
Baseline test: & & 109 & $(3.0-7.5)$ \\
Thyroxine (nmol/l) & & 5.0 & $(0.1-0.9)$ \\
Free triiodothyronine (pmol/l) & & $<0.55$ & \\
Growth hormone (mU/l) & & 0.34 & \\
Insulin-like growth factor-1 (u/ml) & & & \\
\hline
\end{tabular}

Table 2 Haematological investigations

\begin{tabular}{|c|c|c|}
\hline Test & Result & Reference range \\
\hline Haemoglobin $(\mathrm{mg} / \mathrm{l})$ & 14.1 & \\
\hline White blood cell count $\left(\times 10^{9} / 1\right)$ & 7.5 & \\
\hline Platelet count $\left(\times 10^{9} / 1\right)$ & 235 & \\
\hline $\operatorname{ESR}(\mathrm{mm} / \mathrm{h})$ & 23 & \\
\hline Antithrombin III (\%) & 100 & $(80-200)$ \\
\hline Protein C (\%) & 104 & $(70-130)$ \\
\hline \multicolumn{3}{|l|}{ Protein S } \\
\hline Total (\%) & 90 & $(81-113)$ \\
\hline Free $(\%)$ & 39 & $(31-47)$ \\
\hline \multicolumn{3}{|l|}{ Anticardiolipin antibody: } \\
\hline IgG GPL (units/ml) & 5 & $(<7.2)$ \\
\hline IgM MPL (units/ml) & 26 & $(<6.5)$ \\
\hline \multicolumn{3}{|l|}{ Lupus anticoagulant: } \\
\hline APTT (s) & 45 & $(34-46)$ \\
\hline $\begin{array}{l}\text { APTT correction (s) } \\
\text { (80:20 normal:patient) }\end{array}$ & & \\
\hline $\begin{array}{l}\text { (80:20 normal:patient) } \\
\text { Kaolin clotting time (neat) }\end{array}$ & $\begin{array}{l}42 \\
0.8\end{array}$ & $(0.9-1.2)$ \\
\hline Kaolin clotting time $(1: 4)$ & 0.9 & $(0.9-1.1)$ \\
\hline Dilute Russell's viper venom time & 1.21 & $(0.9-1.09)$ \\
\hline Platelet neutralisation procedure & 1.08 & \\
\hline \multicolumn{3}{|l|}{ Autoimmune profile: } \\
\hline n-DNA antibodies (IU/ml) & 98 & $(0-102)$ \\
\hline Extractable nuclear antigen & Negative & \\
\hline Thyroid microsomal antibody (IU/ml) & 227 & $(0-154)$ \\
\hline Thyroglobulin antibody (IU/ml) & 56 & $(0-360)$ \\
\hline
\end{tabular}

Peripheral smear revealed numerous small clumps of platelets and occasional giant platelets. Platelet aggregation test: with agonists such as ADP $\left(2 \times 10^{-5} \mathrm{M}\right.$ and $\left.1 \times 10^{-5} \mathrm{M}\right)$, ristocetin $(1.5$ and $1.0 \mathrm{mg} / \mathrm{ml})$, collagen $(0.19 \mathrm{mg} / \mathrm{ml})$ and arachidonic acid $(0.5 \mathrm{mg} / \mathrm{ml})$ were all normal.

\section{Discussion}

Results of dynamic function tests assessing his hypothalamic-pituitary axis are shown in table 1 and revealed blunted LH, FSH, prolactin and thyroid-stimulating hormone responses. After discontinuation of anticoagulants, thrombophilia screen revealed high titres of anticardiolipin antibodies (ACA) of IgM subtype, a lupus anticoagulant, spontaneous platelet aggregation and giant platelets (shown in table 2). An MRI scan of the head did not reveal a pituitary space-occupying lesion. Dual-energy X-ray absorptiometry (DXA) was employed to obtain values for bone mineral density ( $Z$ scores) and were noted to be 61 and $73 \%$, respectively, in the lumbar vertebrae and hips, compared with agematched controls; this is consistent with generalised osteoporosis. X-Rays of the thoracolumbar spine showed multiple wedgeshaped vertebral body collapses besides extensive demineralisation, especially in the thoracic region, consistent with advanced osteoporosis.

Venous thromboembolic phenomena are some 20 -fold more frequent in Klinefelter's syndrome than in the general population. ${ }^{1,2}$ The nature of thrombophilia in Klinefelter's syndrome has not been adequately characterised, except for a single report describing protein C deficiency. ${ }^{3}$ Our patient presented with pulmonary embolism, and upon investigation, he revealed several procoagulant features such as spontaneous platelet aggregation, giant platelets, a lupus anticoagulant and ACA. Our patient does not yet fulfill the criteria for the antiphospholipid syndrome, which has been defined as the association of recurrent arterial and venous thrombosis, recurrent abortions (in women), thrombocytopenia and ACA, since he has experienced only one thrombotic episode. ${ }^{4,5}$ Antibodies to nuclear DNA in this man were within the normal range and were negative to extractable nuclear antigen, excluding systemic lupus erythematosus. Our patient did not have any clinical or serological evidence of any other non-organ-specific autoimmune syndrome.

ACA may belong to IgG, IgM or IgA class of antibody. ${ }^{6}$ Our patient had significantly higher titres of IgM ACA compared with IgG ACA. The exact biological significance of ACA subclasses is unclear, although IgG subclass is the most prevalent. While it may be tempting to postulate a pathogenetic prothrombotic role for ACA, there is evidence suggesting that ACA synthesis may be an antigen-driven epiphenomenon rather than an autonomous autoimmune process. ${ }^{6,7}$ It could be hypothesised that the injury consequent on the pulmonary embolus in this patient may have exposed cardiolipin antigen, predominantly a component of mitochondrial membranes, and generated an immune response. Such a mechanism would also account for the higher titres of IgM ACA since this class of antibody is the first to rise after an immune challenge. Whether the ACA caused thrombosis or is a 
consequence of injury mediated by thrombosis in this man remains unanswered.

ACAs have variously been described to promote coagulation by several mechanisms such as aggregation of platelets, inhibition of fibrinolysis, inhibition of protein $C$ and $S$ activities as well as by inhibition of the release of arachidonic acid from phospholipid, the latter leading to failure to generate prostacyclin, a powerful antiplatelet aggregant and vasodilatory substance. ${ }^{8-10}$ Qualitative platelet defect of the Bernard-Soulier type has been described with ACA. ${ }^{11}$ The spontaneous platelet aggregation and the lupus anticoagulant activity may both be attributable to the ACA in our patient.

Testosterone stimulates lymphocyte subpopulations such as suppressor $T$ cells and may protect against development of autoimmune diseases accounting for the lower incidence of such disease in men. ${ }^{12}$ Several previous reports have shown increased prevalence of autoimmune diseases in Klinefelter's syndrome. ${ }^{12} \mathrm{We}$ believe that testosterone deficiency, if not causative, may be contributory to the development of the antiphospholipid antibodies in our patient. Klinefelter's syndrome is characterised by hypergonadotropic hypogonadism although rare descriptions of hypogonadotropic hypogonadism, with or without deficiencies of other anterior pituitary hormones, have been described. ${ }^{13}$ Our patient had significant blunting of TSH, prolactin, $\mathrm{LH}$ and FSH responses to releasing hormone stimulation. It is worth emphasising that, although Klinefelter's syndrome is a disease characterised by primary testicular failure, deficiencies of other hormones, especially cortisol and thyroxine sec-

1 Campbell WA, Price WH. Venous thromboembolic diseas in Klinefelter's syndrome. Clin Genet 1981; 19: 275-80.

2 Murray FE. Mesenteric vein thrombosis associated with Klinefelter's syndrome - a case report. Angiology 1988; 39; 45-8.

3 Miller RA, Tremann JA, Ansell JS. The conservative management of renal vein thrombosis. $\mathcal{f}$ Urol 1974; 111: 568-71.

4 Asherson RA, Khamashta MA, Ordi-Ros J, et al. The 'primary' antiphospholipid syndrome: major clinical and serological features. Medicine (Baltimore) 1989; 68: 366-74. 5 Alarcon-Segovia D, Deleze M, Oria CV, et al. Antipho5 Alarcon-Segovia D, Deleze M, Oria CV, et al. Antiphosystemic lupus erythematosus: a prospective analysis of 500 consecutive patients. Medicine (Baltimore) 1989; 68: 353-65.

6 Muir KW. Anticardiolipin antibodies and cardiovascula disease. $¥ R$ Soc Med 1995; 88: 433-6.

7 Triplett DA. Antiphospholipid antibodies and thrombosis: a consequence, coincidence or cause? Arch Pathol Lab Med 1993: 117: 78-88.

8 Carreras LO, De-Freyn G, Machin SJ, et al. Arterial thrombosis, intrauterine death, and 'lupus' anticoagulant. Detection of immunoglubulin interfering with prostacyclin formation. Lancet 1981; 1: 244-6.

9 Comp PC, Deboult LE, Esmon NL, Esmon CT. Human thrombomodulin is inhibited by IgG from two patients with non-specific anticoagulants. Blood 1983; (suppl 1): 1099. ondary to hypopituitarism, not present in our patient, have been shown to occur and must always be excluded in those with inappropriately low gonadotropins. ${ }^{13}$

The prevalence of vertebral osteoporosis in untreated Klinefelter's syndrome is high, although there is no universal agreement that such disease may be prevented by early androgen replacement. ${ }^{14,15}$ Advanced cases such as our patient may require additional therapy with oral calcium and diphosphonates. Although there is little published evidence that such therapy influences the natural history of the disease, it may be argued that the diagnosis should have been made earlier in this man since he was seen regularly by a doctor for his obstructive airways disease and appropriate therapy should have been instituted.

Testosterone has a positive effect on the development of skeletal musculature as well as nitrogen balance. Significant myopathy secondary to testosterone deficiency has been reported rarely ${ }^{16}$ and proximal myopathy has not previously been described with Klinefelter's syndrome. Our patient had painless proximal myopathy presumably secondary to testosterone deficiency in the absence of any other identifiable cause of proximal myopathy.

\section{Final diagnosis}

Antiphospholipid antibodies and pulmonary embolism in a man with Klinefelter's syndrome.

Keywords: antiphospholipid antibodies, pulmonary embolism, Klinefelter's syndrome.

10 Sanfelippo MJ, Drayna CJ. Prekallikrein inhibition associated with lupus anticoagulant: a mechanism of thrombosis. Am f Clin Pathol 1982; 77: 275-9.

11 Beales IL. An acquired pseudo-Bernard Soulier syndrome occurring with autoimmune chronic active hepatitis and anticardiolipin antibody. Postgrad Med f 1994; 70: 305-8.

12 Bizzarro A, Valentine G. DiMatino G Daponte A, DeBli Aizzarro A, Valentine G, DiMatino G, Daponte A, DeBell , Iacona $G$. Influ on clinical ciated with Klinefelter's syndrome. 7 Clin Endocrinol Metab 1987; 64: 32-6.

13 Hughes T, Borsey DQ. Partial hypopituitarism in Klinefelter's syndrome. Br $\mathcal{F}$ Clin Pract 1995; 49: 162-3.

14 Kubler A, Schulz G, Cordes U, Bayer J, Krause U. The influence of testosterone substitution on bone mineral density in patients with Klinefelter's syndrome. Exp Clin Endocrinol 1992; 100: 129-32.

15 Wong FH, Pun KK, Wang C. Loss of bone mass in patients with Klinefelter's syndrome despite sufficient testosterone replacement. Osteoporosis Int 1993;3: 3-7.

16 Orrell RW, Woodrow DF, Barrett MC, et al. Testosterone deficiency myopathy. $f R$ Soc Med 1995; 88: 454-6. 